\title{
Twitter and the Welsh language
}

\begin{abstract}
The emergence of new domains, such as the internet, can prove challenging for minority languages. Welsh is a minority, regional language and is considered 'vulnerable' by UNESCO. The Welsh-speaking community appears to have responded positively to the internet and the new media it facilitates.

This paper uses an online questionnaire to examine the community's response to Twitter. The results show that Twitter has become a new domain for the production and consumption of the Welsh language, as well as facilitating new connections between members of the Welsh-speaking community. However, while Twitter may provide a new domain for the Welsh language, it is also a new domain for the production and consumption of the English language by Welsh-speakers. While the presence of the Welsh language on Twitter should be seen as encouraging, the overall effect of Twitter on the maintenance of the Welsh language remains difficult to determine.
\end{abstract}

Keywords: Twitter, minority language, Welsh, Cymraeg, Social Networking Sites

\section{Introduction}

The measurement of the vitality and degree of endangerment of a minority language is complex and must consider a variety of factors. Among the factors suggested by the UNESCO Ad Hoc Group on Endangered languages (UNESCO, 2003) is the response to new domains and media. If a minority language community cannot respond to the "challenges of modernity" then their language risks becoming "increasingly irrelevant and stigmatized" (UNESCO, 2003, p11). The particular new domains which are important for a specific minority language will vary according to the local context (UNESCO, 2003). New technologies, such as the internet and the new media it facilitates are a challenge of modernity faced by many minority language communities. Eisenlohr (2004, p32) suggests that a presence in new technologies facilitates the "refutation of language ideologies of contempt", establishes an association with modernity and orientation to the future and can demonstrate that a language is relevant to modern lifestyles. This may have particular significance for young speakers of a minority language.

However, the relationship between minority language vitality and both traditional and new media is not straightforward. Firstly, whilst it can be argued that new media in particular provides opportunities for a minority language, they typically also increase exposure to and consolidate the dominance of the majority language (UNESCO, 2003, p11; Cormack, 2007, p59; Cormack, 2013, p255). Secondly, the assumption that increasing the amount and range of media content in a minority language will help the survival of that language is unproven (Cormack, 2007, p58), and there are difficulties in attributing a direct relationship between 
the media and linguistic behaviour (Jones, 2013). Therefore there is a lack of understanding as to the role that traditional and new media might have in language maintenance (Cormack, 2013, p256).

Cormack (2007, p63) suggests that if the media is to have a positive effect on a language it must encourage actual language use. Whilst some new media are essentially traditional media delivered for consumption on a new platform (e.g., BBC television programmes delivered online through their catch-up service iPlayer), other new media (e.g., social networking sites, such as Facebook) are more orientated to participatory interpersonal and inter-social communication (Jones, 2013). Jones suggests that these new social and participatory media need to be considered as distinct from traditional media, for example in Fishman's Graded Intergenerational Disruption Scale (Fishman, 1991). Thus whilst traditional media features in stages 1 and 2, broadly relating to institutional uses of language, new social and participatory media relate to stage 5, the development of literature outside formal and official contexts. Cormack (2010, p136) argues that the transformation of media users from the traditional passive audience to content creators also gives them a role as language planners. In certain local contexts, social networking sites may constitute important new domains with the potential to impact upon the use of a minority language.

Through the use of an online questionnaire, this paper explores part of the Welsh language community's reaction to one social networking site, Twitter. Following a brief review of the Welsh context and overview of Twitter, the paper outlines the Research Questions and the methodology. The results are then presented and discussed and the conclusions provide an overview of the findings.

\section{Context}

Wales is a country with a population of 3 million, situated in the west of the United Kingdom. The Welsh language (Cymraeg) was the only language of the majority of the population of Wales until the mid 1800s (Morgan, 2001). Since that time there has been significant language shift towards English. The 2011 census, the most recent for which results are available, showed there were 562,000 Welsh speakers aged 3+, $19 \%$ of the population (ONS, 2012a). The vast majority of Welsh speakers have native fluency in English. While the rate of decline of the language appears to have slowed over the past few decades, UNESCO considers the language to be 'vulnerable' (Moseley, 2010).

Traditional media continue to be important within Wales, but the internet and its associated new media are also significant. In 2012, $80 \%$ of households in Great Britain had internet access, $93 \%$ of those had a broadband connection and $67 \%$ of adults used a computer everyday (ONS, 2012b). While disaggregated figures for Wales are often not provided in official statistics (and figures for Welsh-speakers are even less common), more than $80 \%$ of adults (aged 16+) in Wales are reported to have used the internet (ONS, 2013b). As McMonagle (2012, p2) suggests, in contexts where the internet has attained 'social and global ubiquity with a tendency towards universalization' it must be having some impact, positive or negative, on minority languages. The Welsh language has been used online since 
at least the late 1980s (Author) and it is currently used across a variety of online applications (Author), but the actual impact of the internet and other new technologies on the language is difficult to determine.

In 2012, $48 \%$ of adults in Great Britain used social networking sites. These sites are particularly popular with young people, with $87 \%$ of 16 to 24 year olds using them. For this age group, using social networking sites is more popular than sending email (ONS, 2013a). According to figures from Twitter (Arthur, 2012), as of May 2012 there were 10 million active Twitter users in the UK - separate figures for Wales are not available.

Twitter (www.twitter.com), which describes itself as 'a real-time information network', is a micro-blogging service and social networking site in which users share short text messages (tweets) of up to 140 characters. Older tweets are constantly displaced by more recent ones in a 'real-time stream' (Berry, 2011) through which information flows in the manner of a stock ticker. Hashtags (\#topic) can be used to group tweets on a particular topic and @ username to refer to or reply to a specific user. A user can follow another account to subscribe to their tweets. The follower relationship is non-symmetric in that A can follow B without B needing to follow A. This follow relationship defines the social network within Twitter. Crystal (2011, chapter 3) presents a more detailed consideration of the core technological facets of Twitter (following the classification scheme proposed by Herring, 2007) as well as exploring its sociological features.

The Twitter interface is available in a number of languages, including Basque and Catalan, but not Welsh. Twitter does not impose any restrictions on the language used by users, who are therefore free to communicate in a minority language should they choose.

The literature relating to the Welsh language on Twitter is limited. Johnson (2013) examined a convenience sample of 500 tweets taken from 25 Welsh-language-using Twitter accounts and found that $41.2 \%$ were in Welsh, $51.2 \%$ were in English, and the remaining 7.6\% were a mix of Welsh and English. Additionally, Johnson found that the more followers a Welsh-speaking user had who were English-speaking only, the more likely a person's general tweets (i.e., tweets directed to a general audience) were to be in English. Author (year) conducted a snowball sample of social networks, using seed points of known Welshlanguage users on Twitter, and tracing their 'following' links to identify other Welshlanguage users. Three iterations identified 731 Welsh-using accounts as of July 2010. An examination of these accounts suggested that Twitter was not widely used in Welsh and that language promotion was not an overt goal of tweeting in Welsh for most users. Indeed, the reasons given for Welsh users' adoption of Twitter were not that dissimilar from reasons given by users of majority languages such as English (e.g., Java et al., 2007).

\section{Research questions}

Due to the lack of existing studies of minority language use on Twitter, which could have informed very specific research questions, the research questions used in this study were framed broadly: 
RQ 1: To what extent do Welsh-speakers arrive at Twitter with the expectation of reading and writing tweets in Welsh?

RQ 2: Does language influence people's choice of who to follow on Twitter?

RQ 3: How do Welsh-speakers find Welsh-language content on Twitter?

RQ 4: What drives the choice of language for a particular tweet?

RQ 5: How does the users' production of Welsh-language content on Twitter compare to their use of the language on other online applications?

In investigating these broad questions the intention was not only to provide some preliminary insights into the use of Welsh on Twitter, but also to inform further, more specific research questions for subsequent studies.

\section{Methodology}

The study used an online questionnaire to gather both quantitative and qualitative data. The questionnaire gathered data from the $15^{\text {th }}$ July 2011 , until the $30^{\text {th }}$ September 2011, 78 days in total. The questionnaire was publicised via Twitter (through both tweets and subsequent retweets), via maes-e (maes-e.com), an online Welsh-language discussion forum, and on Hacio'r Iaith (www.haciaith.com), a blog devoted to technology and the Welsh language. People who used Twitter and spoke Welsh (even if they had only just started learning the language) were invited to complete the questionnaire. As an incentive, respondents could choose to be entered into a prize draw to win an Amazon voucher worth $£ 30$ (about $€ 33 / \$ 47$ ). The questionnaire was anonymous, though respondents were invited to leave their email address if they were willing to be contacted regarding possible participation in a subsequent study.

The questionnaire was available in Welsh and English and consisted of between 16 and 20 closed questions (depending on the number of Twitter accounts used) and two open questions. The questions addressed six main areas of interest: ability to use Welsh; expectations prior to using Twitter; current use of Twitter; how other people's use of Twitter was viewed; Welsh use in other online activities; and optional demographic data. All questions were mandatory except for the demographic questions and one question which was not supported on certain mobile devices.

In total 286 respondents answered at least part of the questionnaire, with 231 completing all the mandatory questions. The optional demographic questions were completed by 226 respondents. To maximise the data under consideration in this paper, all responses are included for every question and the number of responses is indicated.

While the questionnaire provides an insight into some of the individuals who comprise the bilingual Welsh-speaking public on Twitter, the method has limitations. Firstly, the questionnaire was only publicised via a small number of channels. While these channels are popular with Welsh-speakers online, it is likely that a number of Welsh-speaking Twitter 
users were not aware of the questionnaire. A second limitation is that the respondents are a self-selecting sample and therefore may not be representative of Welsh-speaking Twitter users. A third limitation is that the questionnaire relies on self-reported data and in some questions respondents are asked to recall expectations and behaviours from the past. Thus the data may itself be misreported. A final limitation is the small number of responses, which restricts the type of analysis that can be performed and the certainties associated with that analysis. While this is often a problem when studying languages with a small number of speakers, it is worth noting that the sample may be numerically small, but still represent a significant proportion of the population of interest. Estimates suggest that at the time of the study there were approximately 3,000 Twitter accounts where Welsh was being used, according to figures from Indigenous Tweets (n.d.) and Umap Cymraeg (n.d.). If these estimates were correct, then the 313 accounts reported in the current study where Welsh was used for writing would represent around $10 \%$ of that population. However it is not known how many Welsh speakers in total use Twitter, so it is difficult to judge what proportion of that population is represented. In future research it is planned to mitigate some of these limitations through the use of observational data and to develop a richer understanding through more in-depth qualitative work.

\section{Demographic data}

Gender was fairly balanced with $44 \%$ female and $56 \%$ male (226 respondents). The distribution by age is shown in Figure 1, with a mode age of 25-34. A study by Author (year) suggests that Twitter is not particularly popular with young Welsh-speakers aged 13-18, with only $11.5 \%$ of them using it, compared with $87 \%$ using Facebook.

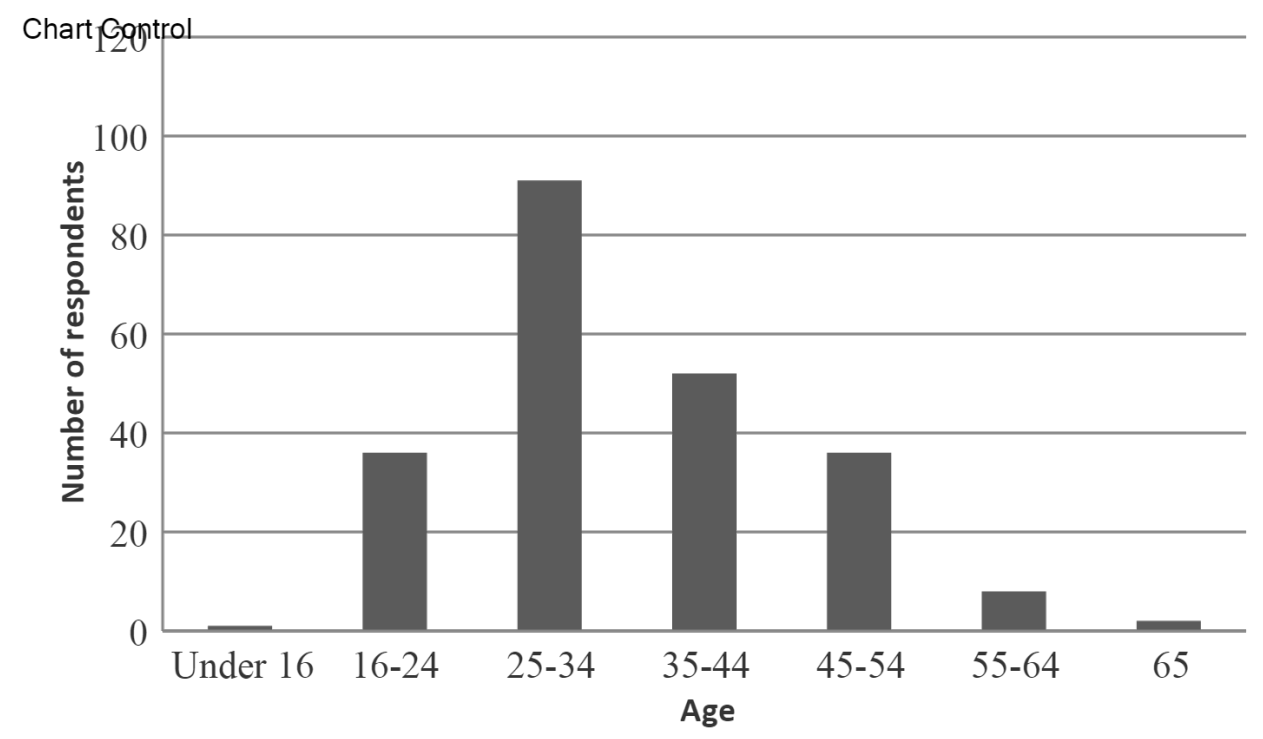

Figure 1. Age range of respondents $(n=226)$.

Of all 286 respondents, 57\% identified Welsh as their first language and 42\% English, with $24 \%$ considering themselves to be Welsh learners. With regard to Welsh language skills, $4.2 \%$ (reading) and $6.3 \%$ (writing) described themselves as not at all fluent, whilst $69.6 \%$ (reading) and $64.0 \%$ (writing) described themselves as totally fluent. 
The extent to which respondents use Welsh in their daily lives is illustrated in Figure 2. As can be seen, only $7.3 \%$ reported no use of the language, while $52.1 \%$ reported spending at least half of the day on average using Welsh. A number of respondents, 15.7\%, reported that they used Welsh all of the day on average. What is clear from the data is that for the large majority of the respondents, Welsh is used to some extent in their day-to-day interactions. Figure 2 shows two peaks, 'up to a quarter' and 'more than three quarters'. It can be speculated that these peaks correlate with people who do or do not work through the medium of Welsh, and/or those people who live in areas of Wales with a higher density of Welsh speakers, and/or those who have Welsh as a language of the home.

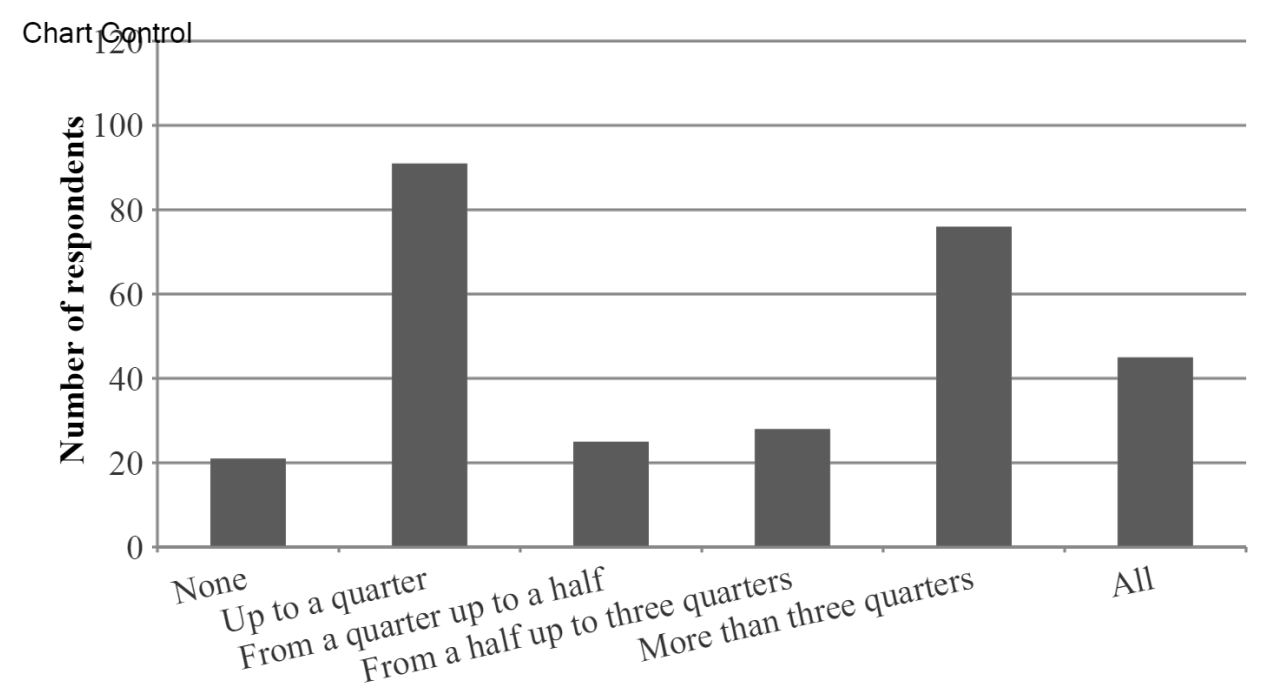

Average proportion of the day spent using Welsh (speaking it, hearing it or writi

Figure 2. Average proportion of the day spent using Welsh $(n=286)$.

The amount of time respondents had been using Twitter varied from less than one month $(n=11)$ to more than three years $(n=28)$. The overall distribution, Figure 3 , suggests that Welsh-speakers on Twitter are more likely to be relatively new to the medium. Most respondents (70\%) used only one Twitter account, $23 \%$ used two and $7 \%$ used three or more $(n=247)$. The use of more than one account was typically due to having a personal account and a work-related account. 


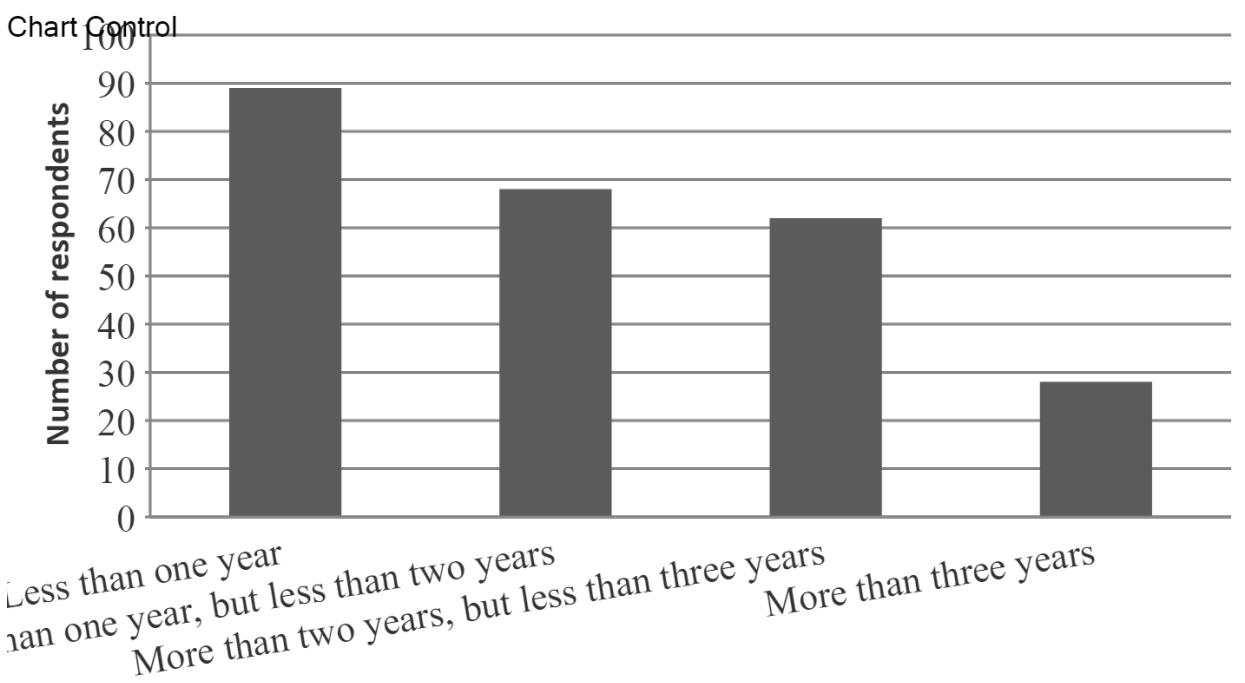

How long using Twitter

Figure 3. Length of time using Twitter $(n=247)$.

\section{Results}

RQ 1: To what extent do Welsh-speakers arrive at Twitter with the expectation of reading and writing tweets in Welsh?

Previous work has theorised the use of Welsh online as an act of 'linguistic resistance' against the dominance of English (Author). In order to explore the extent to which linguistic resistance or language promotion was a motivation for Welsh-speakers joining Twitter, respondents were asked to describe briefly what factor(s) led them to start using Twitter. The definition of 'using Twitter' was deliberately not expanded upon. As respondents were asked to self-define the moment when they started 'using' the application, some might choose to highlight the time they first visited the application, for example to find out more about Twitter prior to deciding whether or not to use it. However, the responses from the majority suggested that they considered themselves to have started 'using' Twitter when they first created a Twitter account.

The 253 responses to this open question were coded using a grounded technique, which made no assumptions about the answers that were likely to have been received. A sample of thirty answers was taken and free-coded independently by the authors. Following discussion, a consensus was then reached on the codebook to be used in further coding. The authors then individually coded the entire response set, using multiple codes per response where appropriate. Once the individual coding had been completed, the three sets of codes were reconciled. Where the same code was selected by two or more of the three coders for a particular response, then that code was considered agreed and was included in the subsequent analysis. In only 5 out of the 253 cases was there no such consensus, necessitating further discussion to decide upon an agreed code. The response codes along with some representative 
examples follow ${ }^{1}$. The percentages shown indicate the percentage of the 253 responses which were coded using that code. The total for the codes adds up to over $100 \%$ as a particular response may have more than one code.

Connect with others (37.9\% of responses): The respondent started using Twitter to keep in touch with friends or make new friends; to communicate with others who have similar views/ideas; and/or to follow celebrities and/or connect with specific fandoms.

Eisiau gweld beth oedd pobl enwog yn gwneud ac roedd ffrindiau i mi yn ei ddefnyddio. [I wanted to see what famous people were doing and my friends were using it.]

Cadw mewn cysylltiad efo ffrindiau dros y byd, datblygu rhwydweithoau newydd, gwneud cysylltiad gydag unigolion eraill gyda doddordebau cyffelyb, bod yn aelod o "gymuned" Gymraeg rhyngwladol [Keeping in touch with friends all over the world, developing new networks, making contact with other individuals with similar interests, being a member of an international Welsh "community"]

I enjoy social networking media. Friends started using it so I followed. Liked the idea of following interesting people - musicians, comedians etc.

Curiosity (33.6\%): The respondent started using Twitter because they had heard about it and were curious about the application.

Eisau gweld beth oedd y 'ffwdan' [I wanted to see what the 'fuss' was]

Dwi'n berson sydd â diddordeb mewn technoleg newydd, felly roeddwn i am arbrofi a darganfod mwy am y system. [I'm a person who is interested in new technology, therefore I wanted to experiment and discover more about the system.]

Share information $(\mathbf{2 2 . 5 \%})$ : The respondent started using Twitter to receive and provide various types of information (websites, ideas, news, etc); this includes information seeking in general.

Rhannu syniadau a barn. Rhannu dolenni i wefannau diddorol. [Sharing ideas and views. Sharing links to interesting websites.]

Roeddwn wedi clywed ar Radio Wales eu bod ar Twitter. Hefyd, roeddwn eisiau cael penawdau Golwg360 ar Twitter. [I heard that Radio Wales was on Twitter. Also I can get Golwg360 (a Welsh language news website) headlines on Twitter]

\footnotetext{
${ }^{1}$ Examples are presented in the original language and the errors that are present have been left uncorrected. The translations are the authors' own. Where an example appears in English only, the respondent chose to comment in English.
} 
Wanted to keep Up-to-date with political news and football news. Mostly interested in political commentators.

Business/work related $\mathbf{2 2 . 5 \%}$ ): The respondent started using Twitter to promote their business or organization and/or themselves in a professional capacity; this includes those who are required to use technology for work-related purposes.

Rhwydweithio proffesiynol - mae cymdeithas sifig Cymru yno. [Professional networking - Wales' civic society is there]

Whilst at university I started using twitter to promote a theatrical performance that was touring Wales. That account was specifically for the production, but afterwards I set-up my own personal account.

Peer pressure/critical mass $\mathbf{( 7 . 5 \% )}$ : The respondent mentioned that they started using Twitter because friends were using the application. This also includes those who joined because they felt that the application was popular, or that 'everyone else was doing it'. This category is distinct from 'connect with others' in that respondents coded here didn't state specifically that they joined Twitter to communicate with friends.

Ffrindiau eraill yn ei defnyddio, yn enwedig cysylltiadau proffesiynol. [Other friends were using it, especially professional contacts]

Everyone else seemed to be using it.

Lot o fy ffrindiau wedi gweud pa mor dda oedd Twitter [Lots of my friends had said how good Twitter was]

Medium/format (5.5\%): The respondent made specific reference to using Twitter because of the characteristics or format of the medium (e.g. messages were short, or the application was easy to use).

Easier than blogging

oherwydd mae dyna'r unug wefan gymdeithasol a fedrir defnyddio ar gyfrifiadiron yr ysgol. [Because it is the only social networking website I am able to use on the school computers.]

Welsh community (4.7\%): The respondent made specific reference to using Twitter to connect with, or share information about, the Welsh cultural community, including (but not limited to) the Welsh language.

Diddordeb yn y Gymraeg a'i diwylliant a gwleidyddiaeth Cymru [Interested in the Welsh language and Welsh culture and politics]

Wedi hen arfer â chyfryngau electronig, roedd Twitter yn apelio a roedd na gymuned gwerth chweil o gymry arno yn barod. [I was well familiar with 
electronic media, Twitter appealed to me and there was a worthwhile community from Wales on there already.]

Doesn't like Facebook (4.7\%): The respondent explicitly mentioned a dislike of Facebook or quitting Facebook as their reason for using Twitter.

Clywed pobl yn son amdano ar y teledu a'r papurau newydd, a gan fy mod I ar Facebook ac yn cychwyn blino ar hwna, teimlais y byddaf yn hoffi steill a symlrwydd twitter. [I heard people mention it on the television and in news papers, I had been on Facebook and was starting to get bored with it, I felt I would like the style and simplicity of Twitter.]

Can't remember (2.0\%): The respondent couldn't recall what made them choose to use Twitter.

Other (1.6\%): A miscellaneous category, used to code rarely occurring reasons, in addition to those responses which could not be understood.

In their work Johnson and Yang (2009) presented respondents with fifteen possible gratifications obtained from their use of Twitter. The three highest scoring were 'Share information with others', 'Get information' and 'See what others are up to'. These first two categories closely match the code of 'Share information' (joint third in our survey, mentioned by $22.5 \%$ of respondents), and the third correlates with 'Connect with others' (our most popular code, mentioned by $37.9 \%$ ). The results suggest that the motivations surrounding Welsh-speakers' use of Twitter are little different to that of any other language group, with social motives and informational motives predominant (Johnson and Yang, 2009). This confirms the general findings of Author (year).

There appears to be little evidence of deliberate 'linguistic resistance' or language promotion, again confirming Author's observations (year). However, a significant number of respondents did state that they were aware of the extent of Welsh use on Twitter in advance of creating an account, demonstrating perhaps that even though they did not primarily join Twitter to use Welsh, it may have been one of the secondary factors influencing their decision. People's use of language in novel online applications such as Twitter is likely to be shaped in part by existing offline and online language behaviours, but also by their expectations and observations of current language use by others within that application. Respondents were asked how many tweets they expected to read and write in Welsh before they started using Twitter. For reading, $13 \%$ expected none, $61 \%$ some, and $26 \%$ had no idea in advance $(n=264)$. For writing, $18 \%$ expected none, $54 \%$ some, and $28 \%$ no idea in advance $(n=263)$. The majority of respondents expected to be both reading and writing in Welsh on Twitter, perhaps further indicating the extent to which Welsh language use online has become normalised and is expected to be used in new online domains.

Previous work has seen Welsh learners as being central to the development of online discussion spaces, particularly when considering the role played by American contributors during the genesis of the language online between 1989 and 1996 (Author). It is interesting to 
note, therefore, that even though $24 \%$ of the entire sample categorised themselves as learning Welsh, only one respondent mentioned that they joined Twitter to assist with their language learning. This result is perhaps surprising considering the relatively low barrier to writing a tweet which can, after all, only be a maximum of 140 characters long; conversely, it could be argued that the highly compressed form of some tweets might make them difficult for those with a low degree of fluency in the language to write, or indeed understand. It may be that participating in a Welsh-speaking community is what is significant to these learners (particularly to those outside Wales) rather than it being seen specifically as a way to learn language.

\section{RQ 2: Does language influence people's choice of who to follow on Twitter?}

One of the fundamental shapers of the experience of using a social networking site (SNS) like Twitter is the network in which an individual user participates. In the case of Twitter this is principally expressed through the non-symmetric 'follow' relationship. Welsh speaking Twitter users might naturally be expected to have non Welsh-speakers in their Twitter network, because of offline friendships, shared interests etc., and are likely to have Welshspeakers in their network for the same reasons.

However, it is interesting to consider whether language might influence the formation of these networks. For a language that has a large number of people using it on Twitter, such as English, it seems unlikely that one English speaker will follow another purely on the grounds that they tweet in English. They are likely to follow someone because of the topics they tweet about, or the way they tweet, or perhaps because of who they are. For a language that has relatively few users on Twitter it may be that a common language is reason enough to follow someone, largely irrespective of the topics they tweet about, or the way they tweet, or who they are.

To explore this possibility, respondents were asked if they were more or less likely to follow someone on Twitter if that person tweeted entirely or mainly in Welsh. Of 240 respondents, $4 \%$ reported a negative influence, $36 \%$ were neutral, and $60 \%$ reported that this would be a positive influence, including $32.9 \%$ who reported they would be 'much more likely to follow them'. This tendency to follow tweeters based on their use of the Welsh language is likely to lead to the creation of networks of Welsh-speakers with relationships that cut across the boundaries of friendship and interest-based networks. Whether this effect is present in other SNS is unknown. The assumption with Facebook has been that the networks of Welsh-speakers will follow the well-observed pattern of mirroring offline social networks and there is some evidence to support this among young Welsh-speakers (Author). If this is the case, then it would appear that the networks created by Welsh-speakers on Twitter may be wider than those created on Facebook, but with potentially weaker ties perhaps more akin to those shared by members of a Facebook group.

It is not known whether non Welsh-speaking English-speakers are less likely to follow someone who tweets in both Welsh and English. If this was the case, then it raises the possibility that there might be a lack of symmetry, with 'follow' relationships from Welsh- 
users to non Welsh-speaking English-speakers which are not reciprocated. This might lead to restricted information flows, with those tweeters who act as language 'bridges' (Herring et al. 2007) linking and translating between the Welsh-speaking and non Welsh-speaking communities.

\section{RQ 3: How do Welsh-speakers find Welsh-language content on Twitter?}

Respondents were asked to reflect on their own use of Twitter and to rank specified methods for finding Welsh-language tweets according to their effectiveness $(\mathrm{N}=192$; this response rate is relatively low because this question was optional as the mechanism for answering it was not supported on certain mobile devices).

1. Reading updates from users you already follow (weighted score 1192)

2. Checking the followers lists of users you already follow (weighted score 959)

3. Typing Welsh words into Twitter's search (weighted score 817)

4. Using Twitters own recommendations of who to follow (weighted score 682)

5. Using other users' Twitter lists (weighted score 608)

6. Using your own Twitter lists (weighted score 577)

7. Using an external website (e.g., Umap, Indigenous Tweets) (weighted score 541)

The fact that the top two most effective methods for finding Welsh-language tweets involve the social network reinforces the view that this is seen (at least in part) as a network of people who share the Welsh language and who are connected with other Welsh-language speakers. The fact that these two methods were ranked above typing Welsh words (including Welsh hashtags) into Twitter's search further supports this view.

\section{$R Q$ 4: What drives the choice of language for a particular tweet?}

The 247 respondents reported having over 339 Twitter accounts used either for reading, writing or both. Of these, 297 were used for reading tweets and 313 for writing tweets. The extent to which this reading and writing was conducted through Welsh is shown in Figure 4.

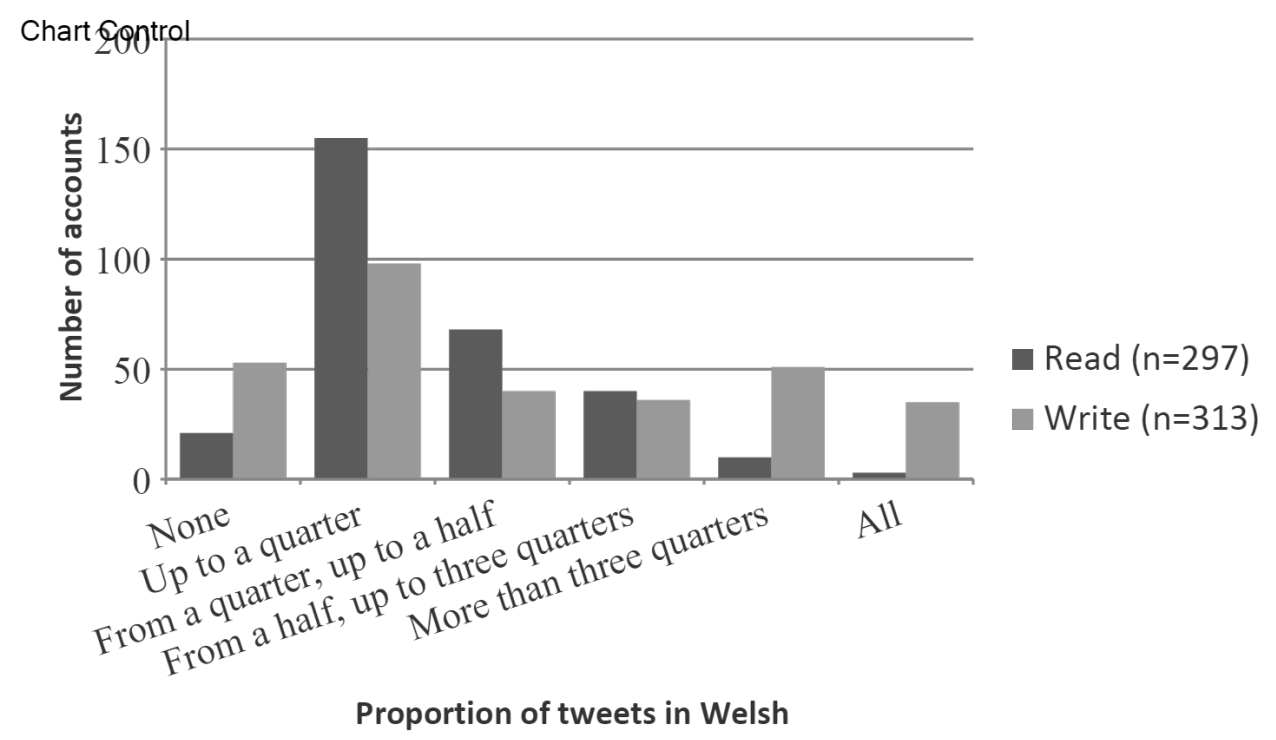


Figure 4. Approximate proportion of tweets read/written in Welsh on each account.

Although the mode proportion of Welsh read and written on Twitter accounts is the same, 'up to a quarter', there appear to be differences in the way that reading and writing are conducted on Twitter. With regard to reading, $7.1 \%$ of the accounts were used to read no Welsh, $75.1 \%$ were used to read a minority of Welsh, and $18 \%$ were used to read a majority of Welsh. Most accounts are used to read at least some Welsh tweets, but in the majority of these Welsh is the minority language. With regard to writing, 17\% of the accounts were not used to write Welsh, $44.1 \%$ were used to write a minority of Welsh and in 39\% Welsh was the major language used. The reasons behind this difference are likely to be complex, including the general linguistic make-up of Twitter, differences in Welsh reading and writing skills, and accounts run for specific purposes or to reach specific audiences. Of the 247 respondents, only seven did not tweet in Welsh in at least one of their accounts.

In common with other bilingual contexts, one of the factors which characterises the Welsh-language community on Twitter is the ability of its members to move fluidly between it and the wider English-language community by virtue of their bilingualism. To gain some insight into this behaviour, respondents were asked to briefly describe what factors would make them more likely to post a particular tweet in Welsh, or if they didn't tweet at all in Welsh, to describe briefly why not.

The 244 responses to this open question were coded using the same grounded technique outlined earlier. The response codes and percentage of responses along with some representative examples follow ${ }^{1}$. The percentages shown indicate the percentage of the 244 responses which were coded using that code. The total for the codes adds up to over $100 \%$ as a particular response may have more than one code.

To direct to a specific audience (54.1\% of responses): The respondent tweets in a particular language to direct their message to a specific audience, whether Welshspeaking or English-speaking.

It depends who I'm tweeting or who I think the topic is most relevant too.

Os dwi eisiau cysylltu gyda person arall sy'n siarad Cymraeg. [If I want to connect with another person who speaks Welsh.]

Topic-related (42.6\%): Respondents stated that they choose the language of the tweet based on the content of the message; for instance that it is related to Wales, or in response to a tweet in a particular language.

Os rwy'n sgwenu am bethau sy'n digwydd yn Ngymru, neu at bobl Cymraeg rwy'n defnyddio cymraeg. [If I'm writing about things which are happening in Wales, or about Welsh people I'll use Welsh.]

\footnotetext{
${ }^{1}$ Examples are presented in the original language and the errors that are present have been left uncorrected. The translations are the authors' own. Where an example appears in English only, the respondent chose to comment in English.
} 
If the tweet were relative to the Welsh language, culture or media; sometimes if related to other Celtic languages or linguistics. I'll occasionally tweet in Welsh if it's related to my current location in Wales, such as my hometown, university, or the weather.

Tweeting in Welsh feels natural (13.1\%): This includes Welsh-speakers who live other aspects of their lives through the language and so feel it natural to tweet in Welsh, in addition to respondents who state that all, or the majority, of their tweets are in Welsh.

Cymraeg yw fy iaith naturiol, teimlo yn rhyfedd yn trydaru fy syniadau/meddyliau/sylwadau yn Saesneg. [Welsh is my natural language, it feels odd to tweet my ideas/thoughts/comments in English.]

Work-related (8.6\%): Respondents tweet in a certain language for work-related purposes.

Ar gyfer gwaith, mae pob trydar gwreiddiol yn Gymraeg ac yn Saesneg oherwydd dyna bolisi'r cwmni. [For work, every original tweet is in Welsh and English because that is the company policy.]

Deliberate choice to tweet in Welsh (8.2\%): Respondents make a conscious choice to tweet in Welsh, whether for language advocacy or because they felt they should.

Mae digon o drydar yn saesneg ar bob pwnc, felly mae'n well gen i ddefnyddio Cymraeg yn unig. [There are enough tweets in English on every subject, therefore I prefer to use only Welsh.]

Language of followers (8.2\%): Respondents stated that their tweeting reflects the language of the majority who follow the account in question.

Nid ydwyf yn dilyn llawer ac mae pawb sy'n fy nilyn i yn siarad Cymraeg [ $I$ don't follow many people and everyone who follows me speaks Welsh]

Doesn't tweet in Welsh (5.8\%): Respondents said they did not generally tweet in Welsh, including those who question whether there are enough Welsh-speakers or accounts using Welsh on Twitter to make it worthwhile to do so.

If I thought there were more Welsh speakers on twitter

Learning Welsh (4.5\%): Respondents are learning Welsh and tweet in Welsh to practice.

Dw i eisiau defnyddio'r iaith Gymraeg mwy achos rydw i'n dysgu, dw i angen ymarfer. [I want to use the Welsh language more because I am learning, I need practice.] 
Other (7.8\%): Reasons mentioned more rarely than those above, or responses which could not be understood.

When considering these results it is important to remember that those who use Welsh on Twitter are bilingual and therefore have the option of engaging with the much larger and more diverse English-speaking community on Twitter. Indeed almost all the respondents engaged with this English-speaking community as well as the Welsh-speaking community. The fact that they choose to engage with the Welsh-speaking community suggests that the language is important, (engagement through the medium of Welsh), and/or the audience are important, (engagement with people who speak Welsh).

Comparing the expectations of reading and writing Welsh on Twitter with the reported frequency of reading and writing Welsh (taking separately the highest Welsh use for reading and for writing from the accounts of each individual respondent) reveals similar patterns for both reading and writing. Of 179 respondents, reported reading of Welsh on Twitter exceeded expectations for $36.3 \%$, equalled it in $46.9 \%$ and fell short of expectations in $16.8 \%$ ( $\mathrm{n}=179$ ). For writing in Welsh on Twitter, expectations were exceeded in $38.5 \%$, equalled for $47.1 \%$ and fell short of expectations in $14.4 \%(n=174)$. However, these figures must be treated with caution for a number of reasons; expectation is reported retrospectively and is for Twitter as a whole, whereas reported actual use is for the single Twitter account in which Welsh is most used. Even allowing for these differences it appears that on individual Twitter accounts, people's use of Welsh exceeded their expectations in more than a third of cases for both reading and writing.

\section{RQ 5: How does the user's production of Welsh-language content on Twitter compare to their use of the language on other online applications?}

Twitter is only one element of the wider online Welsh-language community. Whilst the introduction of a new application such as Twitter will change the overall technological make-up of any online language community, due to the often small number of online users of a minority language the uptake of a new application may have a detrimental effect on the use of an existing application. Respondents' judgement of the relative difficulty in using Welsh in certain online contexts, relative to tweeting, is shown in Figure 5. Of the alternative forms of engagement listed, only writing a blog entry in Welsh was seen as more difficult by the majority. The reasons behind the patterns observed are likely to be a combination of several factors, including the typical length of the text, the typical intellectual depth of the content, and possibly the degree of formality associated with the specific medium. From an initial analysis of the data it is difficult to say whether or not the uptake of Twitter has had a detrimental effect on the use of existing applications or the use of Welsh in those applications. What is clear is that tweeting in Welsh is seen as at least as easy as using Welsh in the alternative applications listed. Twitter may therefore be an effective application in terms of encouraging Welsh-speakers to use the language online. 


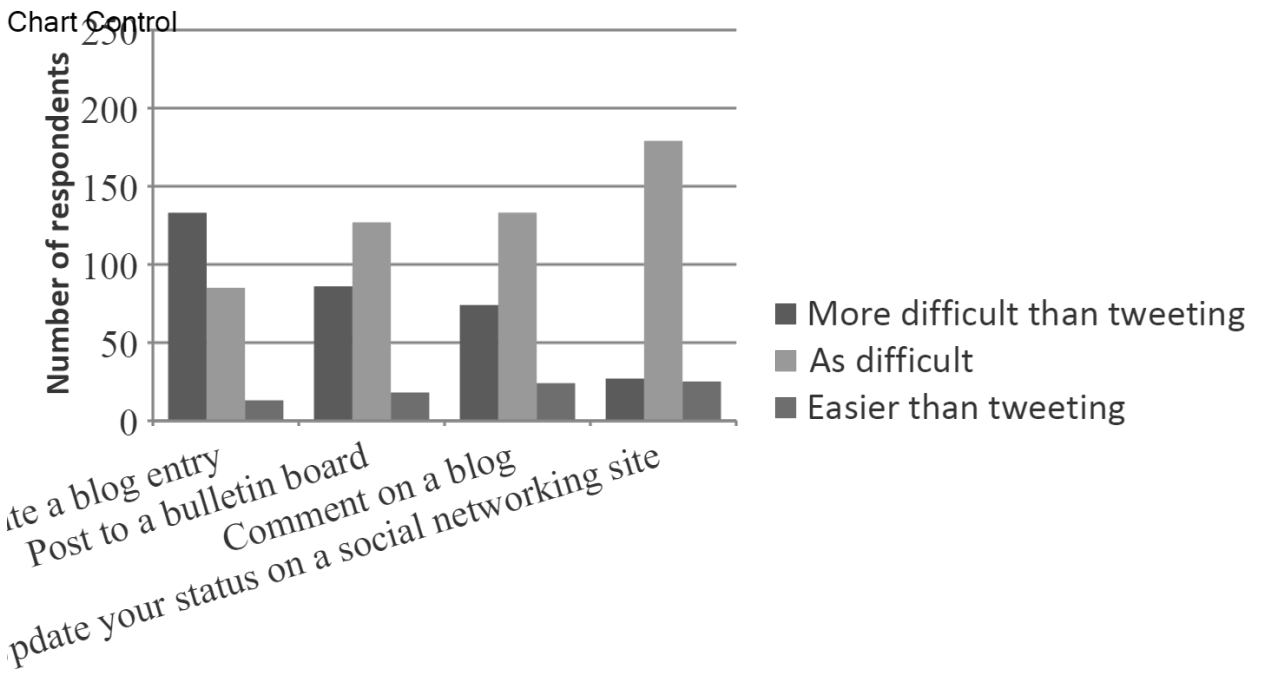

Form of online engagement

Figure 5. Difficulty in engaging online through Welsh, relative to tweeting $(n=231)$.

What is clear from the data is that among the respondents Twitter has become a significant technology for engaging with the online Welsh-language community. As can be seen in Figure 6, tweeting in Welsh was the most popular online Welsh-language producing activity, performed at least once a week. It was also the least likely to be done never. While this is unsurprising in a survey of Twitter users, Twitter appears to be providing a popular and easy way to engage with the online Welsh-language community on a frequent basis.

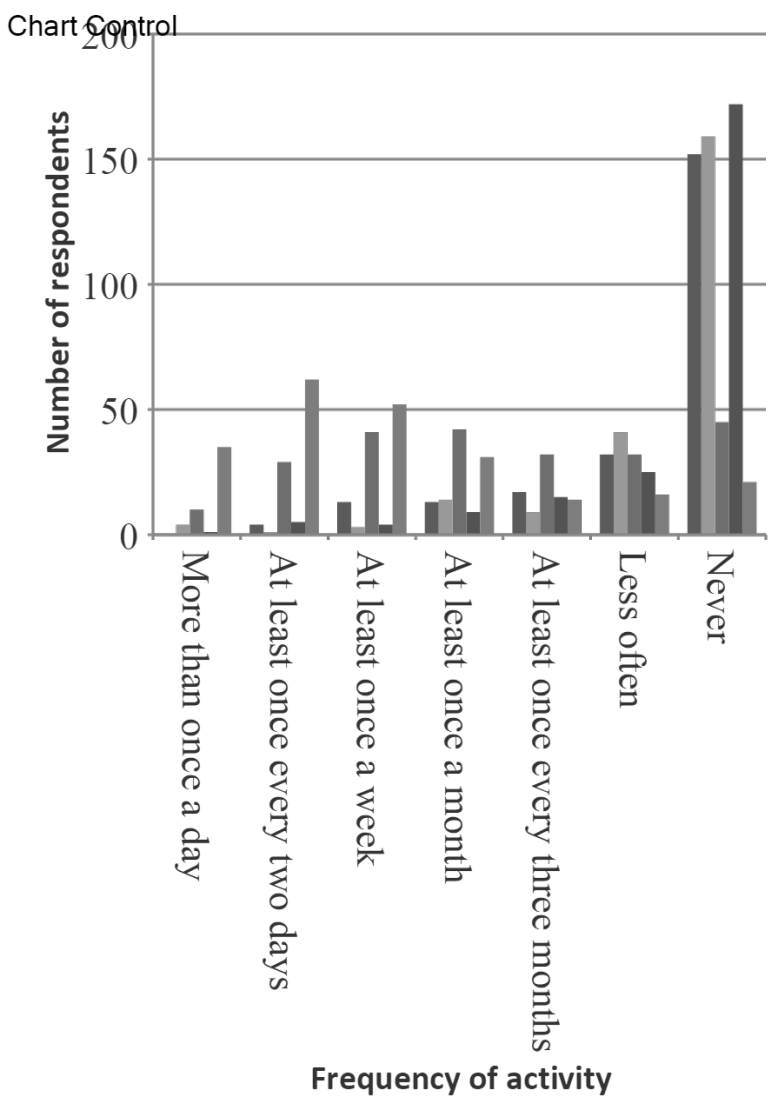

Write a Welsh-language blog entry

Contribute to a Welsh-language bulletin board ( Add a status update in Welsh to a social networ - Upload a Welsh-language video to YouTube update Twitter in Welsh

Frequency of activity 
Figure 6. Frequency of online Welsh-language producing activity $(n=231)$.

As can be seen in Figure 7, SNS and Twitter are the most frequently used online Welsh-language producing activities. Whilst there may be some relationship with their perceived ease of use, there are likely to be a range of other explanatory factors. It is also not clear what interrelationships exist between the different activities, whether one discourages or encourages another, whether their audiences are perceived to be different and so on.

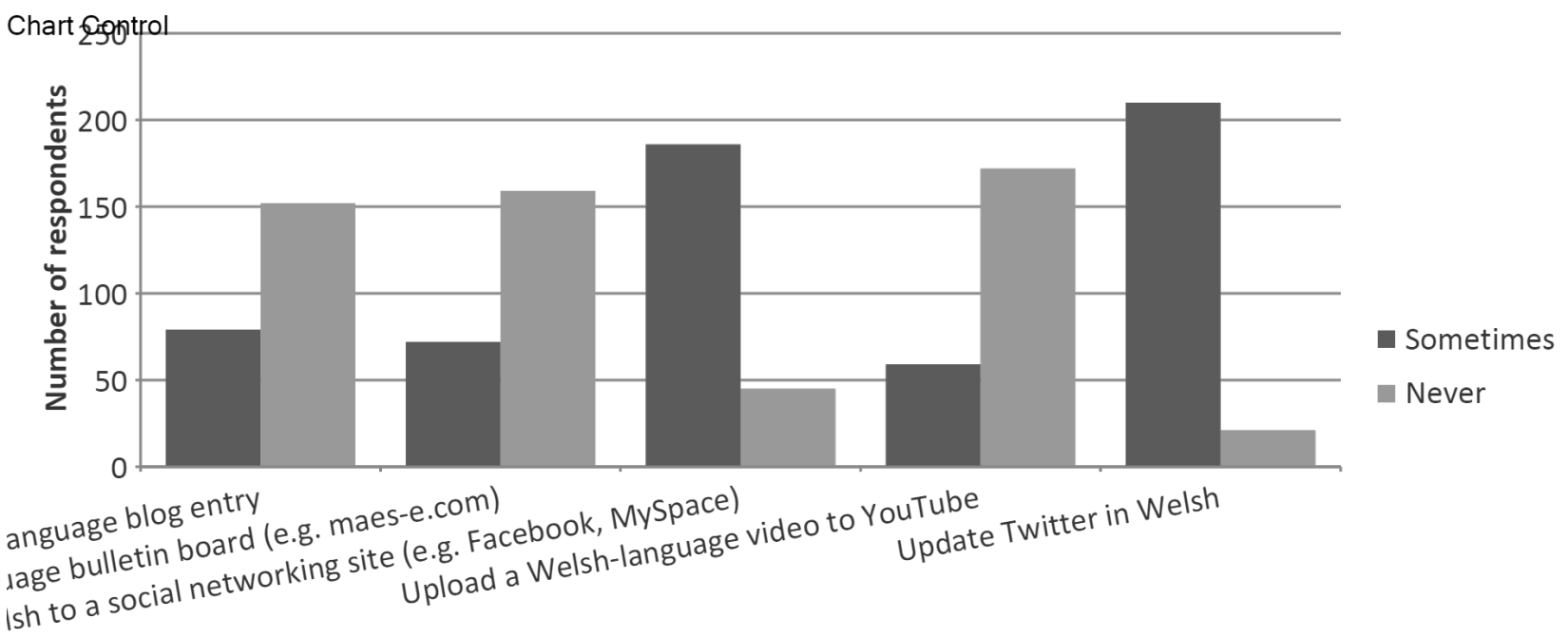

Figure 7. Frequency of online Welsh-language producing activity $(n=231)$.

Figure 8 shows that tweets are made in Welsh more frequently than status updates are made in Welsh on SNS. This may simply be due to the fact that these are Twitter users and it may be that non Twitter users update their SNS status more frequently. Perhaps the use of Twitter means people are less likely to use other SNS or just use them less often. It may be that Twitter is perceived as facilitating real-time social networking, with tweeting happening "in the moment". One respondent gave as their reason for starting to use Twitter the desire to dilyn sylwadau ar dim peldroed wrecsam yn ystod gêm [follow comments about Wrexham football team during the game]. Gruzd et al. (2011) have suggested that Twitter exaggerates "presentism", the belief that only the things that are happening now are what matters (Wellman \& Gulia, 1999). 


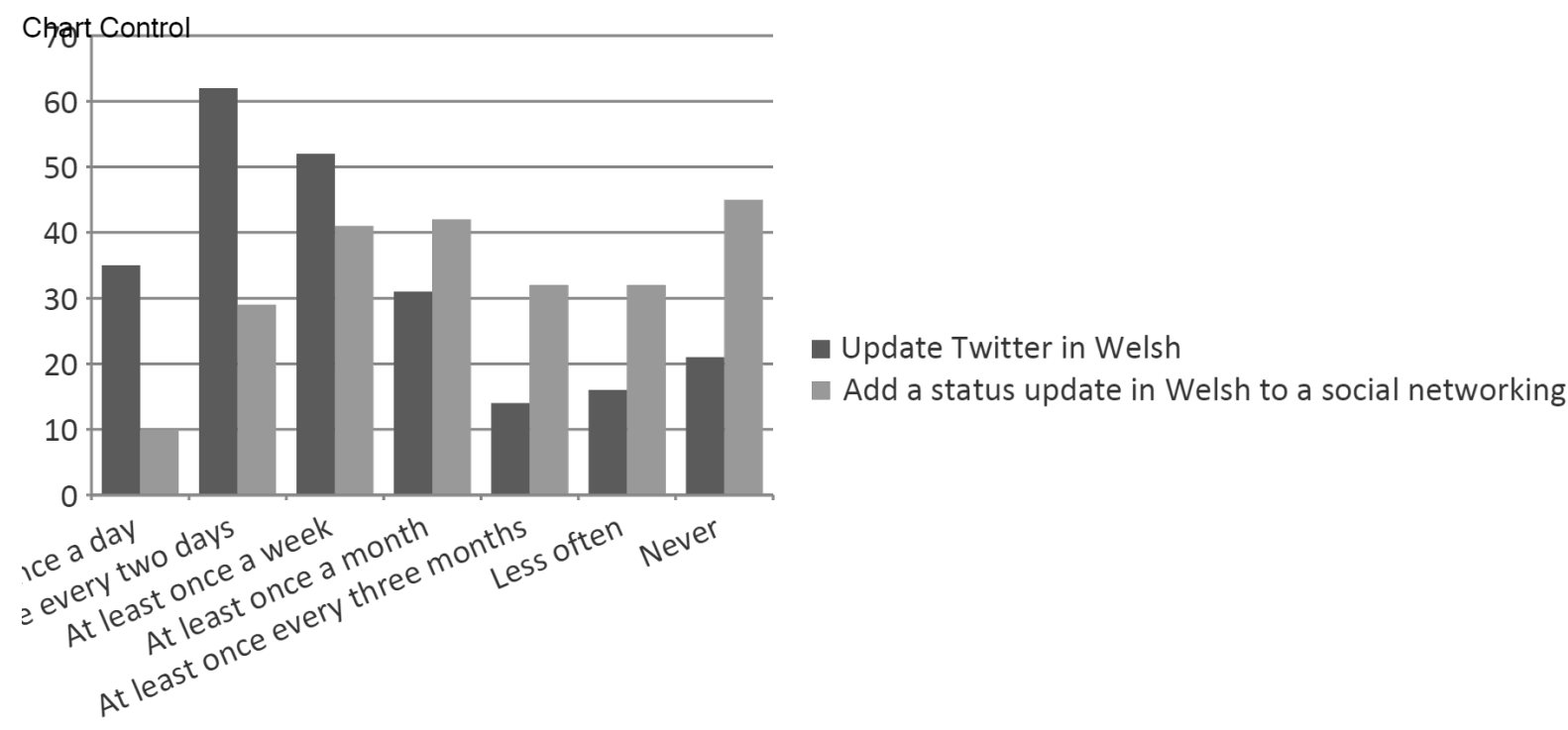

Figure 8. Frequency of updating Twitter and SNS status in Welsh $(\mathrm{n}=231)$.

Another possibility is that this is a language-related behaviour, perhaps these patterns do not hold true for tweeting and status updates in English. It may relate to the different perceptions of audience (known versus unknown / friends versus followers) between different applications. Whilst Twitter is significant in terms of Welsh-language content production and consumption for the respondents, there is still much which needs to be understood about the relationships between the different online Welsh-language producing activities and the influence of both language and audience.

\section{Conclusions}

This paper has presented and discussed the results of a questionnaire administered to Welshspeaking Twitter users. Whilst there are limitations of the study in terms of the distribution of the questionnaire, the self-selecting sample, self-reported data, and the sample size, it provides some initial insights into the response of the Welsh language community to Twitter.

The Welsh language is clearly being used within Twitter, but as with any domain, the response of the Welsh-language community to Twitter is dynamic and evolving. Welshspeakers on Twitter are likely to be relatively new to the medium. However, the number of users and their use of Welsh on Twitter are unlikely to be static, over time any novelty effect will pass, other competing social networking sites may emerge, and so on.

While the majority of users expected to read Welsh on Twitter and to write Welsh on Twitter, using Welsh was not in itself a strong motivation for starting to use Twitter. It appears that the use of the Welsh language online has to a large extent become normalised (at least in some contexts) and that there is an expectation that the language will be used in new online domains as they emerge. This suggests that, for some speakers at least, the Welsh language is associated with modernity and is considered relevant for modern lifestyles. 
There is evidence to suggest that Welsh speakers on Twitter are more likely to follow people who tweet entirely or mainly in Welsh. Thus it appears likely that the networks between Welsh-speakers on Twitter are more likely to cut across the boundaries of typical friendship and interest-based networks. The popular methods for finding Welsh-language content on Twitter reinforces the suggestion that Twitter is seen to support a network of Welsh-speakers who are connected to other Welsh-speakers.

The choice of which language to use for a particular tweet appears to be influenced mainly by the intended audience (as found by Johnson, 2013) and the topic. Only a small number of respondents make a conscious choice to tweet in Welsh, whether for language advocacy or because they felt they should. Given the bilingual nature of almost all Welsh speakers, they can be essentially communicated with as effectively through English as through Welsh, whilst a non Welsh-speaker is likely to find a tweet in Welsh practically unintelligible. Thus while the decision to write a particular tweet in Welsh can be seen as a natural carry-over of everyday language behaviour, it can also be taken as suggesting that the language itself is important, (engagement through the medium of Welsh), and/or the audience are important, (engagement with people who speak Welsh).

Using Welsh on Twitter is perceived to be at least as easy as using Welsh in other common online applications and easier than blogging. Using Welsh on Twitter was also a more frequent activity than using it on other applications. Thus Twitter appears to provide an important domain for the production of Welsh online, both in terms of ease of use and in frequency of output. However it is possible that it may have a negative impact on the use of other social networking sites, such as Facebook or blogging, by Welsh speakers.

Taken together, the findings suggest that Welsh-speakers have adopted Twitter for similar reasons to non Welsh-speakers, and that their natural bilingual language behaviours have continued on Twitter. Thus Twitter has become a new domain for the production and consumption of the Welsh language, as well as providing new connections between members of the Welsh-speaking community. This suggests a positive response to Twitter by the Welsh-speaking community; however the survey does not capture views of those Welshspeakers who do not choose to use Welsh on Twitter.

While Twitter may provide a new domain for the Welsh language, it is also a new domain for the production and consumption of the English language by Welsh-speakers. While the presence of the Welsh language on Twitter should be seen as encouraging, the overall effect of Twitter on the maintenance of the Welsh language remains difficult to determine.

\section{Acknowledgements}

The authors wish to thank the ... for providing the voucher for the prize draw.

\section{References}


Arthur, C. 2012. Twitter now has $10 \mathrm{~m}$ users in UK. The Guardian. http://www.guardian.co.uk/technology/2012/may/15/twitter-uk-users-10m (accessed May 23, 2013).

Berry, D. 2011. Real-Time Streams and the @Cloud. In Stunlaw. http://stunlaw.blogspot.com/2011/01/real-time-streams-and-cloud.html (accessed May 23, 2013).

Cormack, M. 2007. The Media and Language Maintenance. In M. Cormack and N. Hourigan (Eds.) Minority Language Media: Concepts, Critiques and Case Studies. Clevedon: Multilingual Matters. Pp. 52-68.

Cormack, M. 2010. Gaelic in the New Digital Landscape. In G. Munro and I. Mac an Tàilleir (Eds.) Gaelic Communities Today. Edinburgh: Dunedin Academic. Pp. 127-137.

Cormack, M. 2013. Concluding Remarks: Towards an Understanding of Media Impact on Minority Language Use. In E.H.G. Jones and E. Uribe-Jongbloed (Eds.) Social Media and Minority Languages: Convergence and the Creative Industries. Bristol: Multilingual Matters. Pp. 255-265.

Crystal, D. 2011. Internet linguistics: A student guide. Abingdon: Routledge.

Eisenlohr, P. 2004. Language revitalization and new technologies: cultures of electronic mediation and the refiguring of communities. Annual Review of Anthropology, 33; 2145 .

Fishman, J. 1991. Reversing Language Shift. Clevedon: Multilingual Matters.

Gruzd, A., B. Wellman and Y. Takhteyev. 2011. Imagining Twitter as an imagined community. American Behavioral Scientist, 55 (10), 1294-1318.

Herring, S. 2007. A faceted classification scheme for computer-mediated discourse.

Language@Internet, 4, article 1. http://www.languageatinternet.org/articles/2007/761 (accessed May 23, 2013).

Herring S. C., J. C. Paolillo, I. Ramos-Vielba, I. Kouper, E. Wright, S. Stoerger, L. A. Scheidt and B. Clark. 2007. Language networks on LiveJournal. In Proceedings of the 40th Hawai'i International Conference on Systems Sciences.

Indigenous Tweets, n.d. http://indigenoustweets.com/ (accessed May 23, 2013).

Java, A., S. Song, T. Finin and B. Tseng. 2007. Why we twitter: understanding microblogging usage and communities. In Proceedings of the Joint 9th WEBKDD and 1 st SNA-KDD Workshop. http://ebiquity.umbc.edu/paper/html/id/367/Why-WeTwitter-Understanding-Microblogging-Usage-and-Communities (accessed May 23, 2013).

Johnson, I. 2013. Audience design and communication accommodation theory: use of Twitter by Welsh - English biliterates. In E.H.G. Jones and E. Uribe-Jongbloed (Eds.) Social Media and Minority Languages: Convergence and the Creative Industries. Bristol: Multilingual Matters. Pp. 99-118. 
Johnson, P. R. and S.-U. Yang. 2009. Uses and Gratifications of Twitter: An Examination of User Motives and Satisfaction of Twitter Use. Presented at AEJMC 2009, Communication Technology Division. Boston, Massachusetts. http://citation.allacademic.com/meta/p_mla_apa_research_citation/3/7/6/3/6/pages 376 367/p376367-1.php (accessed May 23, 2013).

Jones, E.H.G. 2013. Minority Language Media, Convergence Culture and the Indices of Linguistic Vitality. In E.H.G. Jones and E. Uribe-Jongbloed (Eds.) Social Media and Minority Languages: Convergence and the Creative Industries. Bristol: Multilingual Matters. Pp. 58-72.

McMonagle, S. 2012. The European Charter for Regional or Minority Languages: Still Relevant in the Information Age? Journal on Ethnopolitics and Minority Issues in Europe, 11, no. 2: 1-24.

Morgan, G. 2001. Welsh: A European case of language maintenance. In The Green Book of Language Revitalization in Practice, eds. L. Hinton and K. Hale. San Diego, Academic Press, 107-13.

Moseley, C. (ed.) 2010. Atlas of the World's Languages in Danger, 3rd edn. Paris, UNESCO Publishing.

Online

version. http://www.unesco.org/culture/en/endangeredlanguages/atlas (accessed May 23, 2013).

Office for National Statistics, 2012a. 2011 Census: First Results on the Welsh Language. http://wales.gov.uk/docs/statistics/2012/121211sb1182012en.pdf (accessed May 23, 2013).

Office for National Statistics, 2012b. Internet Access - Households and Individuals, 2012 part 1. http://www.ons.gov.uk/ons/dcp171778_275775.pdf (accessed May 23, 2013).

Office for National Statistics, 2013a. Internet Access - Households and Individuals, 2012 part 2. http://www.ons.gov.uk/ons/dcp171778_301822.pdf (accessed May 23, 2013).

Office for National Statistics, 2013b. Internet Access Quarterly Update, Q4 2012. http://www.ons.gov.uk/ons/dcp171778_300874.pdf (accessed May 23, 2013).

Umap Cymraeg, n.d. http://cy.umap.eu (not available, May 23, 2013).

UNESCO (2003). Language Vitality and Endangerment. Report by the UNESCO Ad Hoc Expert Group on Endangered Languages. http://www.unesco.org/culture/ich/doc/src/00120-EN.pdf (accessed May 23, 2013).

Wellman, B. and M. Gulia. 1999. Net Surfers Don't Ride Alone: Virtual Communities as Communities. In B. Wellman (Ed.), Networks in the Global Village. Boulder, CO: Westview, pp. 331-366. 